\title{
Altered Pattern of Macrophage Polarization as a Biomarker for Severity of Childhood Asthma
}

\author{
Chang-Hung Kuo ${ }^{1,2}$ \\ Mei-Lan Tsai ${ }^{3}$ \\ Chung-Hsiang $\mathrm{Li}^{2,4}$ \\ Hui-Pin Hsiao ${ }^{4}$ \\ Mei-Chyn Chao ${ }^{4}$ \\ Ming-Sheng Lee ${ }^{4}$ \\ Yi-Ching Lin $^{5-8}$ \\ Chih-Hsing Hung (iD) $3,4,9$ \\ 'Ta-Kuo Clinic, Kaohsiung, Taiwan; \\ ${ }^{2}$ Department of Pediatrics, Kaohsiung \\ Municipal Ta-Tung Hospital, Kaohsiung, \\ Taiwan; ${ }^{3}$ Graduate Institute of Medicine, \\ College of Medicine, Kaohsiung Medical \\ University, Kaohsiung, Taiwan; \\ ${ }^{4}$ Department of Pediatrics, Kaohsiung \\ Medical University Hospital, Kaohsiung \\ Medical University, Kaohsiung, Taiwan; \\ ${ }^{5}$ Department of Laboratory Medicine, \\ Kaohsiung Medical University Hospital, \\ Kaohsiung Medical University, Kaohsiung, \\ Taiwan; ${ }^{6}$ Department of Laboratory \\ Medicine, School of Medicine, College of \\ Medicine, Kaohsiung Medical University, \\ Kaohsiung, Taiwan; ${ }^{7}$ Ph.D. Program in \\ Toxicology, College of Pharmacy, \\ Kaohsiung Medical University, Kaohsiung, \\ Taiwan; ${ }^{8}$ Substance and Behavior \\ Addiction Research Center, Kaohsiung \\ Medical University, Kaohsiung, Taiwan; \\ ${ }^{9}$ Department of Pediatrics, Kaohsiung \\ Municipal Hsiao-Kang Hospital, \\ Kaohsiung, Taiwan
}

Correspondence: Chih-Hsing Hung Department of Pediatrics, Kaohsiung Municipal Hsiao-Kang Hospital, No. 482,

Shanming Road, Siaogang District,

Kaohsiung, 812, Taiwan

Tel +886-7-3I 2 II $10 \mathrm{I}-6506$

Fax +886-7-321393।

Email pedhung@gmail.com
Purpose: Asthma causes a substantial morbidity and mortality burden in children and the pathogenesis of childhood asthma is not completely understood. Macrophages are heterogeneous with divergent M1/M2 polarization phenotypes in response to various stimulations during the inflammatory process. We aimed to investigate the pattern of macrophage polarization and its association with severity and exacerbation in asthmatic children.

Patients and Methods: Normal and asthmatic children aged 4-18 years were enrolled for 12 months. Children with asthma were further subgrouped according to their severity and the requirement for hospitalization during exacerbations. Clinical data were obtained from medical records. Peripheral blood samples were collected to analyze macrophage polarization, including M1, M2, and subsets, by flow cytometry.

Results: Fifty-one asthmatic cases and 27 normal controls were included in this study. The level of $\mathrm{PM}-2 \mathrm{~K}^{+} \mathrm{CD} 14^{+}$but not $\mathrm{PM}-2 \mathrm{~K}^{+} \mathrm{CD} 14^{-}$was decreased in asthmatic children. The levels of $\mathrm{M} 2 \mathrm{a}\left(\mathrm{CCR} 7^{-} \mathrm{CXCR} 1^{+}\right), \mathrm{M} 2 \mathrm{~b}\left(\mathrm{CCR} 7^{-} \mathrm{CD} 86^{+}\right)$, and $\mathrm{M} 2 \mathrm{c}\left(\mathrm{CCR} 7^{-} \mathrm{CCR} 2^{+}\right)$subsets, but not M1 $\left(\mathrm{CCR} 7^{+} \mathrm{CD} 86^{+}\right)$, were increased in asthmatic children. The levels of M1 were decreased, but the levels of M2c were increased, in children with moderate asthma compared to those with mild asthma. The levels of $\mathrm{PM}-2 \mathrm{~K}^{+} \mathrm{CD} 14^{+}$cells and $\mathrm{M} 1$ subsets were decreased, but the M2c subset cells were increased in asthmatic children requiring hospitalization during exacerbations.

Conclusion: Macrophage polarization may be involved in the pathogenesis of childhood asthma and is a potential biomarker of childhood asthma disease severity.

Keywords: M2 macrophage polarization, asthma severity, asthma exacerbation, childhood asthma hospitalization

\section{Introduction}

Asthma and allergic diseases are the most common chronic inflammatory diseases in children, causing a substantial morbidity and mortality burden. In severe cases, the symptoms are frequently not controlled, even with intensive guideline-based therapy. ${ }^{1}$ There is still a lack of complete understanding of the pathogenesis of asthma. Therefore, biomarkers for the evaluation and intervention of severe asthma in children are needed.

CD 14 is a glycoprotein strongly expressed on the cell surface of monocytes and macrophages and it plays a critical role in the activation of innate immune activity and the Toll-like receptor (TLR) signaling pathway. ${ }^{2}$ Previous research revealed that human monocytes were identified as classical monocytes (high CD14 expression) and nonclassical monocytes (low CD14 expression). Classical monocytes promote innate immune responses such as phagocytosis, cell adhesion, and migration, whereas 
nonclassical monocytes mediate primarily complement and Fc gamma-mediated phagocytosis with adhesion. ${ }^{3}$ Monocyte-derived macrophages are believed to be important in the asthmatic airway, although their mechanisms of action remain to be defined. ${ }^{4}$ Macrophages dynamically take part in the initial stage of inflammation and the late stage of resolution. ${ }^{5,6}$ To identify mature tissue macrophages and distinguish macrophages from other monocyte-derived cell populations, $\mathrm{PM}-2 \mathrm{~K}$ was recently developed as a marker for the culture of human macrophages. ${ }^{7}$ The validity of PM-2K as a marker of macrophages has been proven in alveolar macrophages isolated from human lung biopsy samples. ${ }^{7}$ I In response to pathogen and allergen stimulation, alveolar macrophages are polarized into classically activated macrophages (M1 cells) and alternatively activated macrophages (M2 cells). M1 cells express proinflammatory cytokines such as TNF- $\alpha$ and IL- $1 \beta$ to induce lung inflammation and tissue damage. M2 cells can be further divided into M2a, $\mathrm{M} 2 \mathrm{~b}$, and M2c subsets in different microenvironments. M2a cells produce the allergy-related cytokines IL-4 and IL-13, whereas M2c cells produce the anti-inflammatory cytokine IL-10. ${ }^{8,9} \mathrm{M} 2 \mathrm{a}$ and $\mathrm{M} 2 \mathrm{c}$ cells are involved in the initiation, inflammation resolution, and tissue remodeling in the various stages of asthma. ${ }^{10}$ Our previous study showed that the patterns of circulating macrophage polarization in peripheral blood are associated with the severity, lung function, and control status of adult asthma patients. ${ }^{11}$

Currently, it is known that the pathogenesis, phenotypes, and factors associated with severity are quite different between childhood and adult asthma. ${ }^{12}$ However, the roles of circulating macrophages and their subsets, M1 and M2 macrophages, in the pathogenesis of childhood asthma remain unclear. In the present study, we revealed, for the first time in the literature, that circulating macrophages and their subsets M1, M2a, M2b, and M2c are associated with severity as well as exacerbations that require hospitalization of children with asthma.

\section{Materials and Methods}

\section{Study Population and Isolation of Monocytes}

The study population enrolled patients with childhood asthma from the outpatient departments of 3 hospitals belonged to Kaohsiung Medical University including one medical center (Kaohsiung Medical University Hospital) and two community hospitals (Kaohsiung Municipal Ta-Tung Hospital; Kaohsiung Municipal Hsiao-Kung Hospital) in southern Taiwan. Patients who met the following inclusion criteria were eligible for enrollment: 1 . under the age of 18 years of age, and 2 . physician-diagnosed asthma. Physicians' diagnosis of asthma and its severity were made according to an operational description suggested by the Global Initiative for Asthma (GINA) guidelines. Patients with other serious systemic diseases, such as congenital heart diseases, neuromuscular disorders, or autoimmune diseases, were excluded. Normal subjects were enrolled from among children who visited the outpatient department for routine health examinations or vaccination.

The severity of asthma and asthma exacerbations were defined according to step therapy in the Global Initiative for Asthma (GINA) guidelines, as in our previous studies. Patients receiving step 1 and 2 therapy were defined as having mild asthma, whereas patients receiving step 3 therapy were defined as having moderate asthma. The criteria for hospitalization for patients with asthma exacerbation at the emergency department (ED) or outpatient department (OPD) were based on the suggestions from the guidelines for inpatient treatment during asthma exacerbations. The flowchart of the patient enrollment criteria is summarized in Figure 1.

The protocol was approved by the Institutional Review Board of Kaohsiung Medical University Hospital (KMUHIRB 20130037). All participants provided their written informed consent signed by their parents or legal guardians. This study was conducted in accordance with the Declaration of Helsinki. After informed consent was obtained, peripheral blood samples were obtained from the healthy individuals and asthmatic patients. Nested casecontrol comparisons were implemented, depending on the availability of the respective samples at the time of analysis.

\section{Flow Cytometry}

A multicolor flow cytometric method was established to identify and distinguish circulating macrophages, which were defined by the expression of PM- $2 \mathrm{~K}$ in the Ficollisolated peripheral blood mononuclear cells (PBMCs) of study patients; appropriate isotype controls were used. PBMCs were sequentially stained with human $\mathrm{Fc}$ receptor binding inhibitor (eBioscience), purified anti-macrophage antibody (PM-2K, Serotec), and anti-mouse IgG-FITC. After washing, the cells were stained with purified antiCXCR1 antibody (eBioscience) followed by anti-mouse IgG-Qdot 585 (Thermo Fisher Scientific, Waltham, USA). After another wash, the cells were stained with CD3-Pacific blue (UCHL1, BD Biosciences, San Jose, CA, USA), CD19Pacific blue (HIB19, eBioscience), CD14-PE/Cy7 (61D3, 


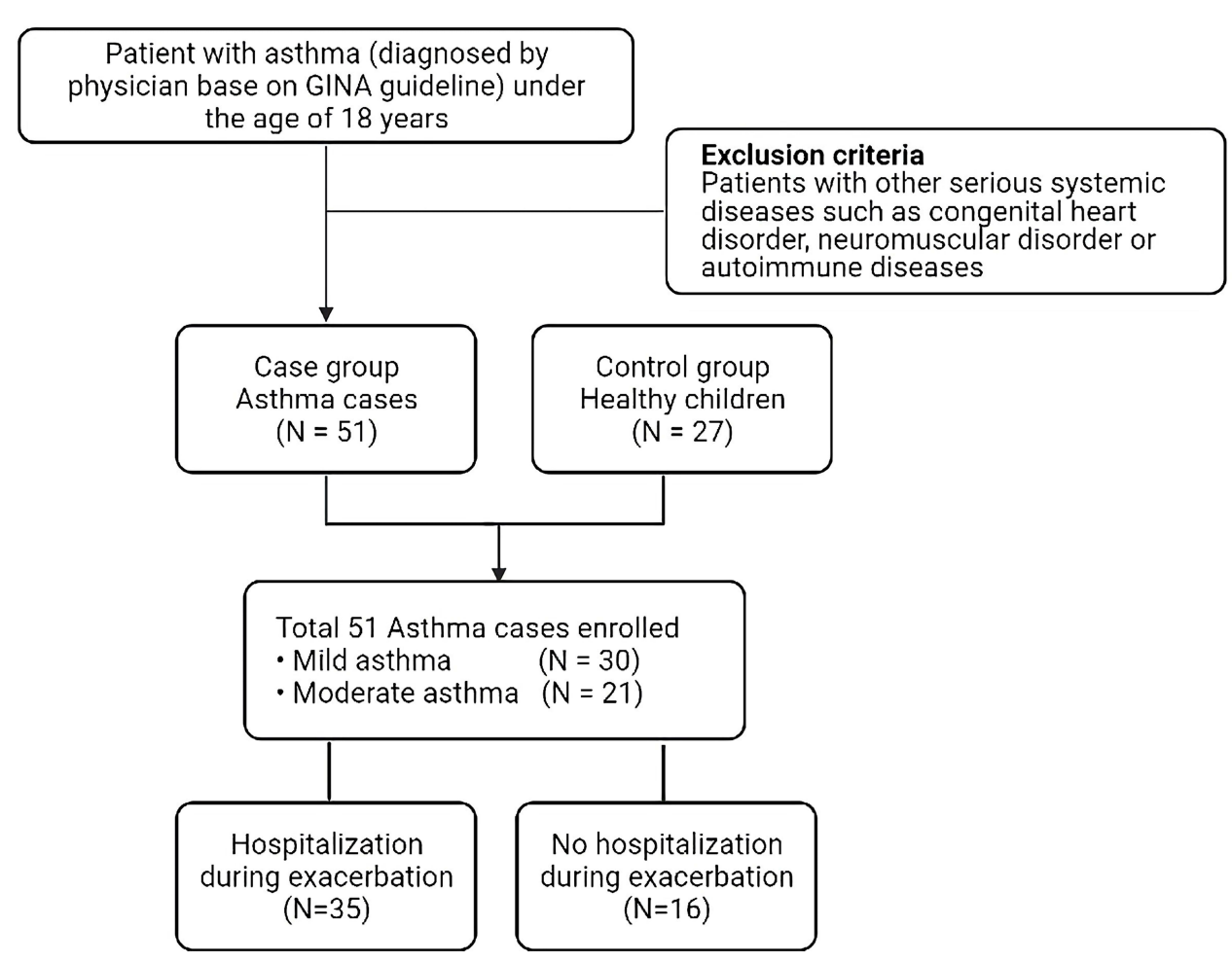

Figure I Flow chart of patient enrollment.

eBioscience), CCR7-APC (Miltenyi Biotec, Bergisch Gladbach, Germany), CD86-PerCP (B7-2, BioLegend, California USA), CCR2-PE (K036C2, BioLegend), and the appropriate isotype controls in PBS containing $0.5 \%$ fetal bovine serum. The samples were run on an LSRII flow cytometer (BD Biosciences, San Jose, CA) and analyzed using FlowJo software (Tree Star, Inc., Ashland, OR). Representative flow cytometry plots are shown for several groups, including healthy children, children with mild asthma, and children with moderate asthma (Figure 2).

\section{Statistical Analysis}

Statistical analysis was performed using GraphPad Prism (Version 5, GraphPad Prism Software, Los Angeles, CA, USA). The Mann-Whitney $U$-test was used to determine the difference between normal subjects and patients. The KruskalWallis test with post hoc Dunn's multiple comparison test was used to determine the differences between subgroups of patients.

\section{Results}

In the case-control study population, 51 asthmatic children and 27 normal controls were enrolled. There was no significant difference in age or sex distribution between the cases and controls (Table 1).

\section{Phenotypic Characterization of Circulating PM-2K ${ }^{+}$Subsets in Peripheral Blood Mononuclear Cells (PBMCs)}

To examine the heterogeneity of the circulating $\mathrm{PM}-2 \mathrm{~K}^{+}$ macrophages, we chose markers including CD14 (monocyte/macrophage axis), CD86 (maturation marker), and CCR7 (homing receptor). In the staining pattern, $10^{6}$ live macrophage cells were acquired first, and then these cells were gated by forward and side scatter properties as Gate 1. We observed that PM- $2 \mathrm{~K}^{+}$cells could be divided into two subsets based on their CD14 expression (PM$2 \mathrm{~K}^{+} \mathrm{CD} 14^{+}$and $\mathrm{PM}-2 \mathrm{~K}^{+} \mathrm{CD} 14^{-}$subsets); therefore, we separated the above cells into three groups: nonT and nonB $\left(\mathrm{CD}^{-} \mathrm{CD}^{-} 9^{-}\right.$) cells (Gate 2$)$, $\mathrm{PM}-2 \mathrm{~K}^{+} \mathrm{CD} 14^{+}$macrophages (Gate 3), and $\mathrm{PM}-2 \mathrm{~K}^{+} \mathrm{CD} 14^{-}$macrophages (Gate 4). We further divided these macrophages into four groups against the fluorescence minus one (FMO) control as follows: $\mathrm{M} 1$ cells $\left(\mathrm{CCR} 7^{+} \mathrm{CD} 86^{+}\right), \mathrm{M} 2 \mathrm{a}$ cells $\left(\mathrm{CCR} 7^{-} \mathrm{CXCR}^{+}\right), \mathrm{M} 2 \mathrm{~b}$ cells $\left(\mathrm{CCR} 7^{-} \mathrm{CD}^{+} 6^{+}\right)$, and $\mathrm{M} 2 \mathrm{c}$ cells $\left(\mathrm{CCR} 7^{-} \mathrm{CCR}^{+}\right)$. 


\section{Control}
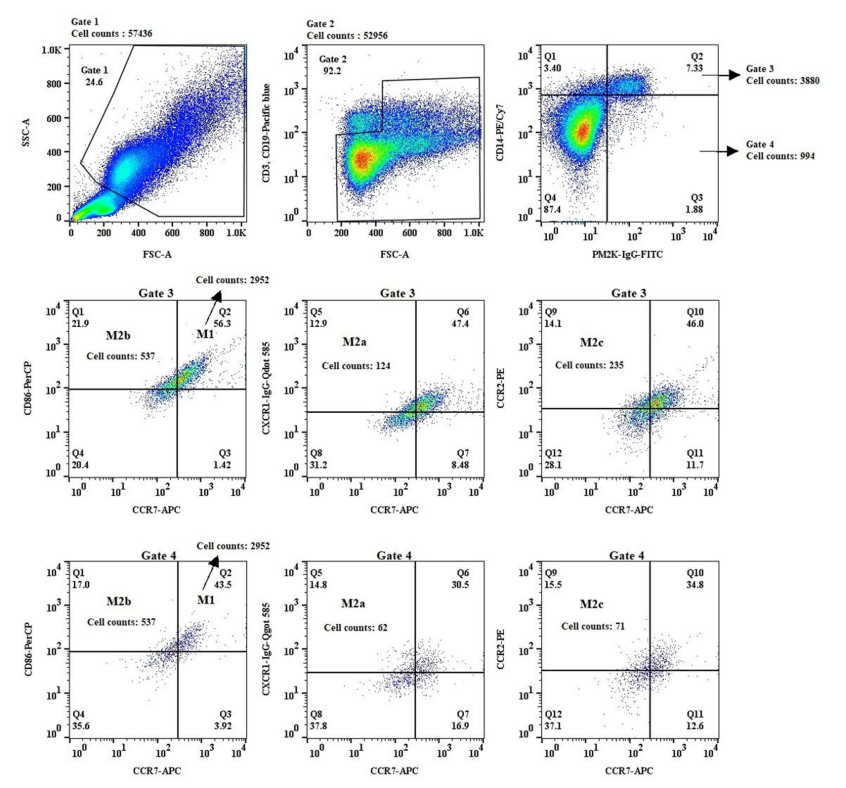

Mild
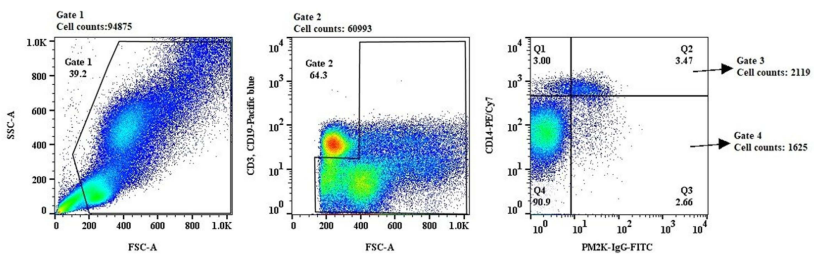

Moderate
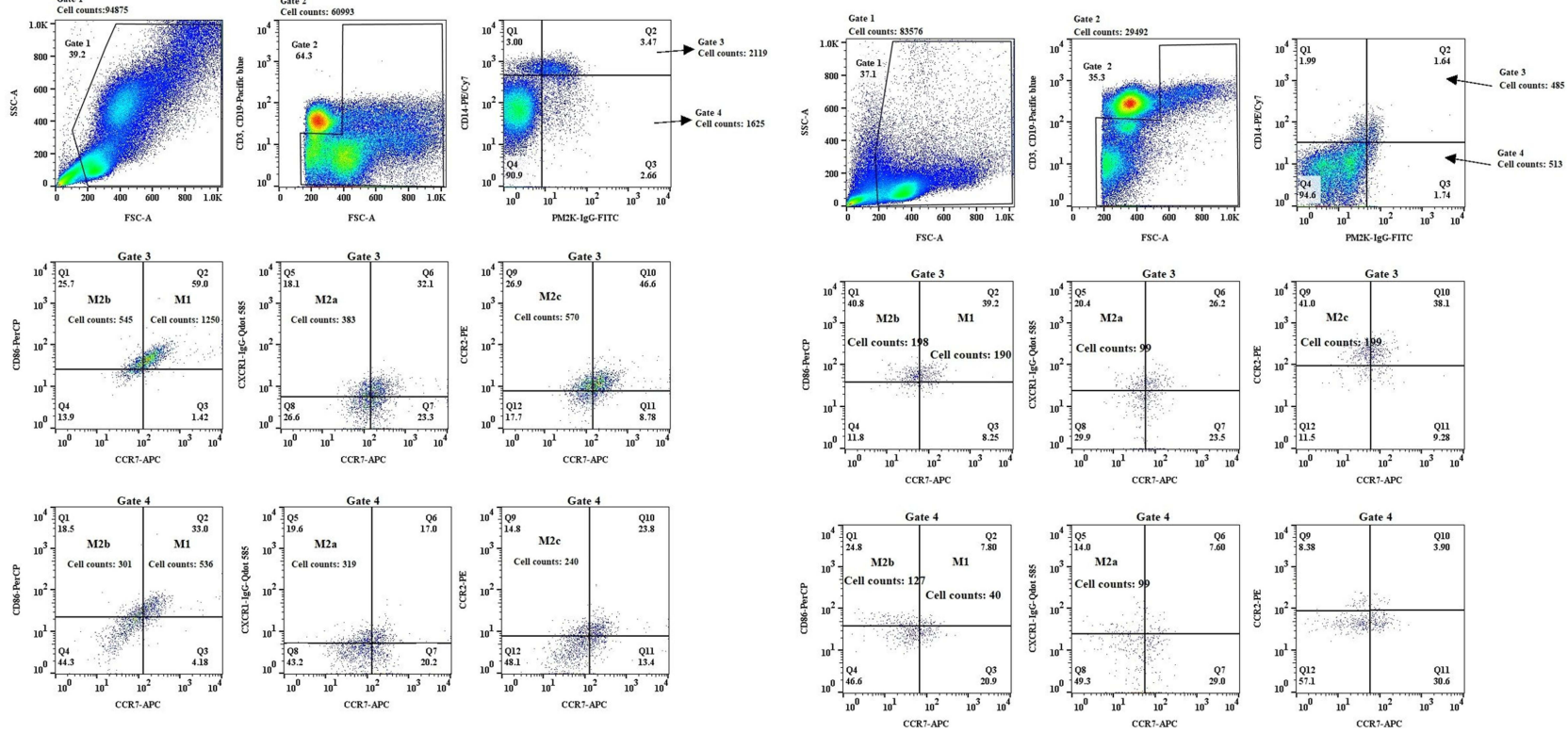

Figure 2 Identification of circulating PM-2K+ cells in peripheral blood and the subsets using a multi-color flow cytometric method by different gating strategies and a combination of fluorochrome-conjugated antibodies. Representative flow cytometry plots were shown from a healthy group, mild asthma group, and moderate asthma group respectively.

\section{The Levels of PM-2K ${ }^{+}$Cells in Peripheral Blood Were Decreased in Asthmatic Children}

As shown in Figure 3, the levels of $\mathrm{PM}-2 \mathrm{~K}^{+} \mathrm{CD} 14^{+}$macrophages (Figure $3 \mathrm{~A}$ ), but not $\mathrm{PM}-2 \mathrm{~K}^{+} \mathrm{CD} 14^{-}$macrophages (Figure 3B), were significantly decreased in asthmatic children in comparison to those in normal healthy children.
The Levels of the MI Macrophage Subset Were Similar in the Peripheral Blood of Asthmatic and Normal Healthy Children

We next investigated whether the pattern of macrophage polarization was different in asthmatic and normal healthy children. Macrophages expressing CCR7+CD86+ cells were defined as the M1 subset according to our previously 
Table I Baseline Characteristics of Control and Asthmatic Children

\begin{tabular}{|c|c|c|c|c|}
\hline & Control $(\mathrm{N}=27)$ & \multicolumn{2}{|c|}{ Asthma Case $(\mathrm{N}=5 \mathrm{I})$} & $P$ value \\
\hline Boy & 9 (33.3\%) & \multirow{2}{*}{\multicolumn{2}{|c|}{$\begin{array}{l}28(51.0 \%) \\
23(48.9 \%)\end{array}$}} & \\
\hline Girl & $18(66.7 \%)$ & & & \\
\hline Age & & & & 0.086 \\
\hline Mean, yr ( $\pm S D)$ & $8.93( \pm 2.63)$ & \multicolumn{2}{|c|}{$7.65( \pm 3.80)$} & \\
\hline Asthma Severity & & Mild & Moderate & $* 0.011$ \\
\hline Boy & & $12(23.5 \%)$ & $16(31.4 \%)$ & \\
\hline Girl & & $18(35.3 \%)$ & $5(9.8 \%)$ & \\
\hline Asthma mean age & & & & 0.208 \\
\hline Mean, yr $( \pm S D)$ & & $8.17( \pm 4.43)$ & $6.90( \pm 2.6 I)$ & \\
\hline IgE level & & & & 0.0797 \\
\hline $\mathrm{KU} / \mathrm{L}$ & & 383.2 & 1043 & \\
\hline Hospitalization & & No & Yes & 0.051 \\
\hline Boy & & $16(31.4 \%)$ & $12(23.5 \%)$ & \\
\hline Girl & & $19(37.3 \%)$ & $4(7.8 \%)$ & \\
\hline Age & & & & 0.076 \\
\hline Mean, yr $( \pm S D)$ & & $8.29( \pm 4.11)$ & $6.25( \pm 2.62)$ & \\
\hline Asthma Treatment & & Mild & Moderate & \\
\hline Montelukast & & II (2I.6\%) & & \\
\hline Low dose ICS & & $4(7.8 \%)$ & & \\
\hline Montelukast + ICS & & & $16(31.4 \%)$ & \\
\hline$L A B A+I C S$ & & & $5(9.8 \%)$ & \\
\hline
\end{tabular}

Notes: *Represent $p<0.05$. Data were expressed as mean \pm standard deviation (SD).

Abbreviations: ICS, inhaled corticosteroids; LABA, long-acting beta-agonist.

published study. ${ }^{8}$ As shown in Figure 3, we found that there was no difference in the levels of the M1 subset in both $\mathrm{PM}-2 \mathrm{~K}^{+} \mathrm{CD} 14^{+}$cells (Figure $3 \mathrm{C}$ ) and $\mathrm{PM}-2 \mathrm{~K}^{+} \mathrm{CD} 14^{-}$ cells (Figure 3D) between asthmatic and normal healthy children.

\section{The Levels of M2 Subsets of PM-2K $+\mathrm{CDI} 4+$ Macrophages, Including M2a, $M 2 b$, and M2c Macrophages, Were Increased in Asthmatic Children}

In contrast to the results of the M1 subset, the levels of M2a (CCR7 ${ }^{-} \mathrm{CXCR}^{+}$; Figure $\left.4 \mathrm{~A}\right), \mathrm{M} 2 \mathrm{~b}\left(\mathrm{CCR} 7^{-} \mathrm{CD} 86^{+}\right.$; Figure $4 \mathrm{~B})$, and $\mathrm{M} 2 \mathrm{c}\left(\mathrm{CCR} 7^{-} \mathrm{CCR} 2^{+}\right.$; Figure $\left.4 \mathrm{C}\right)$ subsets of $\mathrm{PM}-2 \mathrm{~K}^{+} \mathrm{CD} 14^{+}$macrophages were significantly higher in asthmatic children. However, the levels of M2a, M2b, and M2c subsets of PM-2 $\mathrm{K}^{+} \mathrm{CD} 14^{-}$macrophages were not significantly different between asthmatic and normal healthy children (Figure 4D-F).

\section{Macrophage Subsets Discriminated the Severity of Asthmatic Children}

Next, we investigated whether the levels of macrophage subsets are different in asthmatic children with varying severity. The levels of $\mathrm{PM}-2 \mathrm{~K}^{+} \mathrm{CD} 14^{+}$(Figure 5A) and $\mathrm{PM}-2 \mathrm{~K}^{+} \mathrm{CD} 14^{-}$(Figure 5B) macrophages were not significantly different between mild and moderate asthmatic children. Interestingly, the levels of the M1 subsets of both $\mathrm{PM}-2 \mathrm{~K}^{+} \mathrm{CD} 14^{+}$(Figure $5 \mathrm{C}$ ) and $\mathrm{PM}-2 \mathrm{~K}^{+} \mathrm{CD} 14^{-}$ (Figure 5D) macrophages were significantly decreased in children with moderate asthma in comparison to 
A

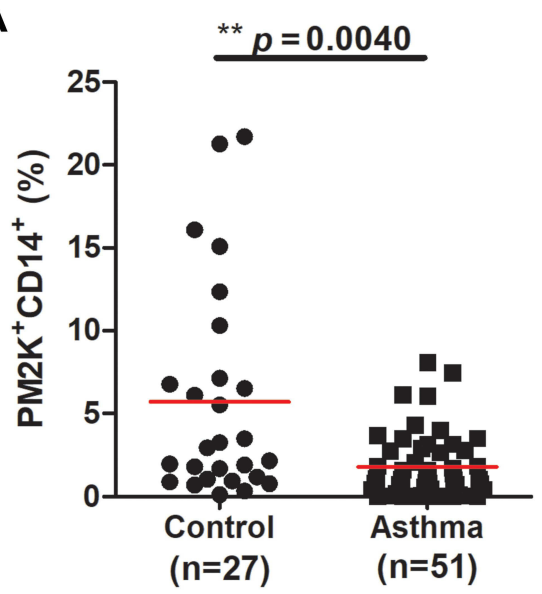

C

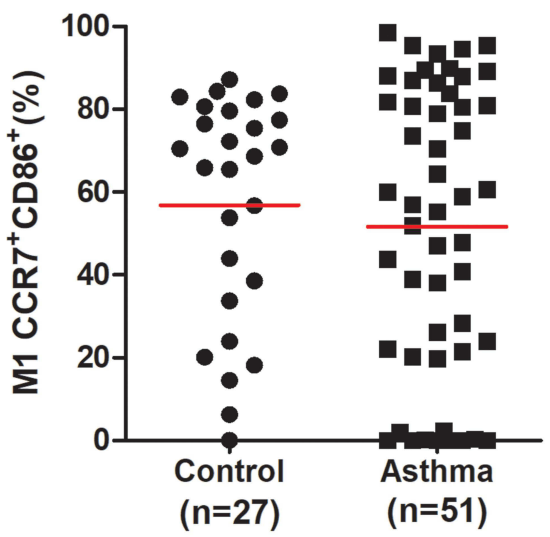

B

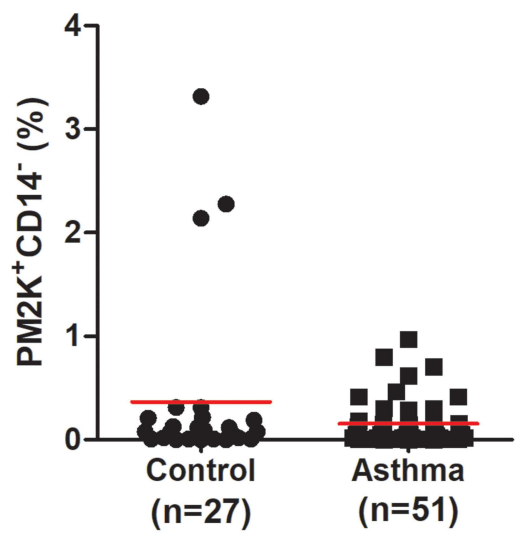

D

$\mathrm{PM}^{+} \mathrm{K}^{+} \mathrm{CD} 14^{-}$Group

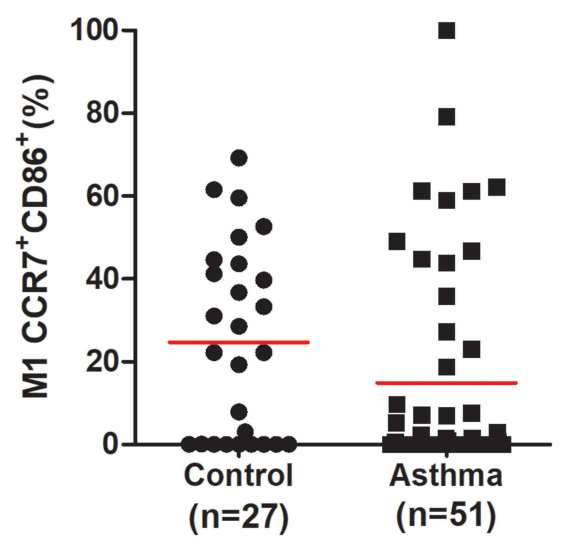

Figure $3 \mathrm{PM}-2 \mathrm{~K}^{+} \mathrm{CDI} 4^{+} / \mathrm{PM}-2 \mathrm{~K}^{+} \mathrm{CDI} 4^{-}$macrophage and their $\mathrm{MI}$ subset in asthmatic and healthy children. $(\mathrm{A})$ The levels of $\mathrm{PM}-2 \mathrm{~K}^{+} \mathrm{CDI} 4^{+}$macrophage were decreased in asthmatic children. (B) The levels of PM- $2 \mathrm{~K}^{+} \mathrm{CDI} 4^{-}$macrophage were not different between asthmatic and healthy children. (C) The levels of PM-2 $\mathrm{K}^{+} \mathrm{CDI} 4^{+} \mathrm{MI}$ subset were not different between asthmatic and healthy children. (D) The levels of PM- $2 \mathrm{~K}^{+} \mathrm{CDI} 4^{-}$MI subset were not different between asthmatic and healthy children. **Represent $\mathrm{p}<0.0 \mathrm{I}$. Data were expressed as mean \pm standard deviation (SD).

those in children with mild asthma. Regarding the M2 subsets, the levels of M2c (Figure 5G) but not M2a (Figure 5E) or $\mathrm{M} 2 \mathrm{~b}$ (Figure 5F) in $\mathrm{PM}-2 \mathrm{~K}^{+} \mathrm{CD} 14^{+}$ macrophages were significantly increased in children with moderate asthma in comparison to those in children with mild asthma. Similarly, regarding M2 subsets in $\mathrm{PM}-2 \mathrm{~K}^{+} \mathrm{CD} 14^{-}$macrophages, only the levels of M2c (Figure 5J) were significantly increased in children with moderate asthma in comparison to those in children with mild asthma. In contrast, the levels of M2a (Figure 5H) were borderline decreased in children with moderate asthma in comparison to those in children with mild asthma.

\section{Macrophage Subsets Discriminated} Against Asthmatic Children Requiring Hospitalization During Exacerbation

Based on the findings that the levels of macrophage subsets were associated with severity in asthmatic children, we investigated whether the levels of macrophage subsets in asthmatic children were associated with the requirement for hospitalization during asthma exacerbations. Interestingly, we found that the level of $\mathrm{PM}-2 \mathrm{~K}^{+} \mathrm{CD} 14^{+}$ (Figure 6A) was decreased in asthmatic children requiring hospitalization during exacerbations. Moreover, the levels of the M1 subsets of both PM- $2 \mathrm{~K}^{+} \mathrm{CD} 14^{+}$(Figure 6C) and $\mathrm{PM}-2 \mathrm{~K}^{+} \mathrm{CD} 14^{-}$(Figure 6D) macrophages were 
A

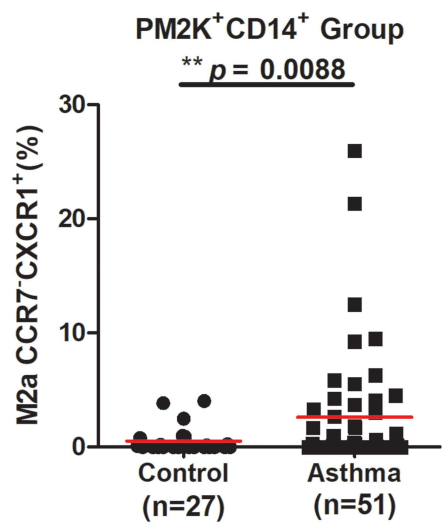

D

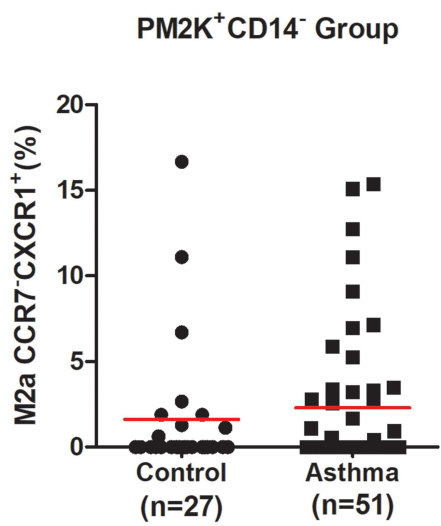

B

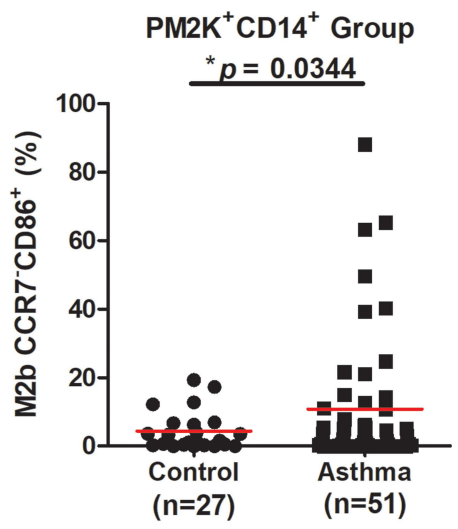

E

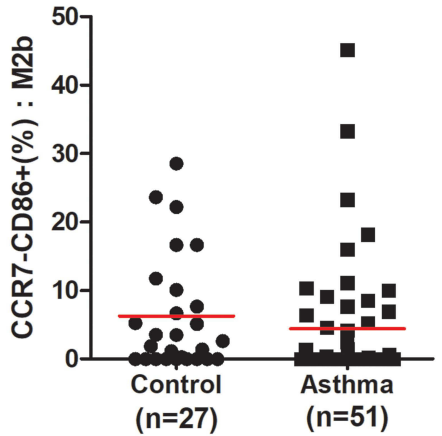

C

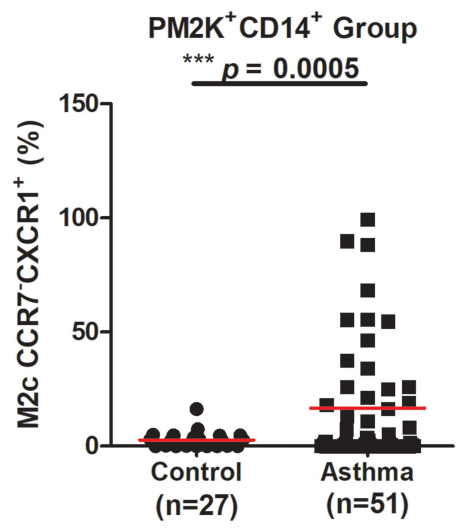

$\mathbf{F}$

$\mathrm{PM}^{2} \mathrm{~K}^{+} \mathrm{CD} 14^{-}$Group

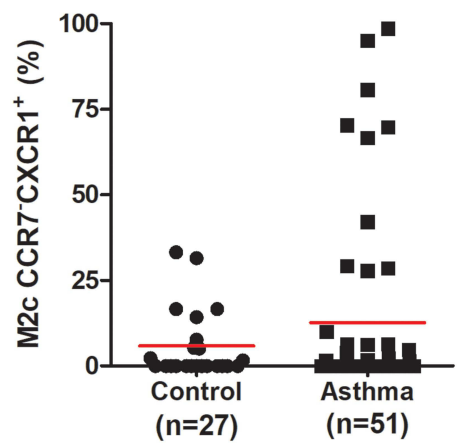

Figure $4 \mathrm{PM}-2 \mathrm{~K}^{+} \mathrm{CDI} 4^{+} / \mathrm{PM}-2 \mathrm{~K}^{+} \mathrm{CDI} 4^{-}$macrophages $\mathrm{M} 2$ subsets in asthmatic and healthy children. The levels of PM-2K ${ }^{+} \mathrm{CDI} 4^{+}$macrophage subsets $\mathrm{M} 2 \mathrm{a}(\mathrm{A}), \mathrm{M} 2 \mathrm{~b}(\mathrm{~B})$, and $M 2 c(C)$ were increased in asthmatic children. The levels of PM-2K ${ }^{+} C D / 4^{-}$macrophage subsets M2a (D), M2b (E), and M2c (F) were not significantly different between asthmatic and healthy children. *Represent $\mathrm{p}<0.05$, **Represent $\mathrm{p}<0.0 \mathrm{I}$, and ***Represent $\mathrm{p}<0.00 \mathrm{I}$. Data were expressed as mean \pm standard deviation (SD).

significantly decreased in asthmatic children requiring hospitalization. Regarding M2 subsets, the levels of M2c (Figure 6G), but not M2a (Figure 6E) or M2b (Figure $6 \mathrm{~F}$ ), of $\mathrm{PM}-2 \mathrm{~K}^{+} \mathrm{CD} 14^{+}$macrophages were significantly increased in asthmatic children requiring hospitalization during exacerbations. Similarly, only the levels of M2c (Figure 6J) but not M2a (Figure 6H) or M2b (Figure 6I) in PM-2K ${ }^{+} \mathrm{CD} 14^{-}$macrophages were significantly increased in asthmatic children requiring hospitalization during exacerbations.

\section{The Levels of $M 2 c$ Subsets in Both PM- $2 \mathrm{~K}^{+} \mathrm{CDI} 4^{+}$and $\mathrm{PM}-2 \mathrm{~K}^{+} \mathrm{CD} / 4^{-}$ Macrophages Were Increased in Patients with Higher IgE Levels}

$\mathrm{IgE}$ is critically involved in allergic asthma in children. We next investigated the association between IgE and macrophage subsets in children with asthma. As shown in
Figure 7, we found that the levels of M2c in PM$2 \mathrm{~K}^{+} \mathrm{CD} 14^{+}$(Figure $7 \mathrm{G}$ ) and $\mathrm{PM}-2 \mathrm{~K}^{+} \mathrm{CD} 14^{-}$macrophages (Figure 7J) but not other subsets were increased in patients with higher IgE levels.

\section{Discussion}

Childhood asthma is considered to be a specific phenotype with a predominant T-helper (Th) type 2 immune reaction and inflammation. ${ }^{12}$ In the present study for the first time in the literature, we found that the pattern of macrophage polarization was altered in children with asthma, and the polarization subsets M1/M2 distinguished the severity of asthma. Furthermore, the specific subsets of macrophage polarization were associated with the requirement for hospitalization during asthma exacerbations. These findings suggest the key role of macrophage polarization in the pathogenesis of childhood asthma and the possible clinical applications of these findings as useful biomarkers in the management of childhood asthma. 
A

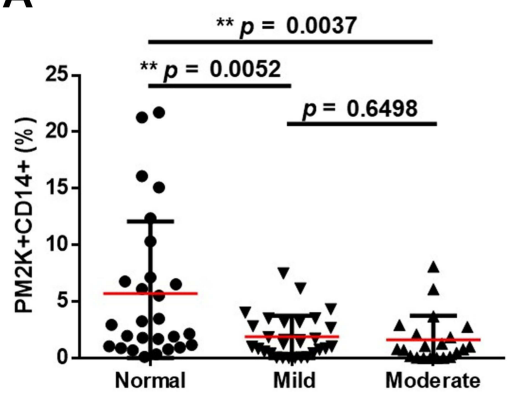

C

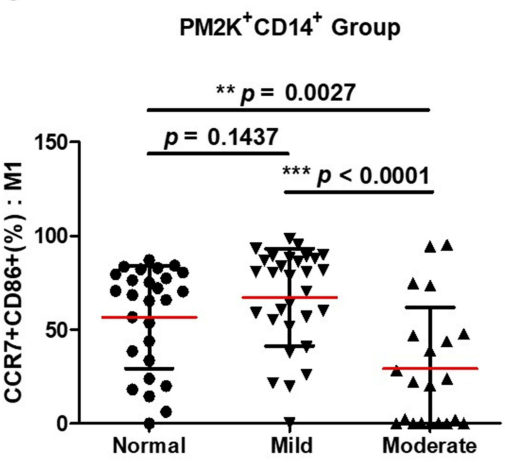

E

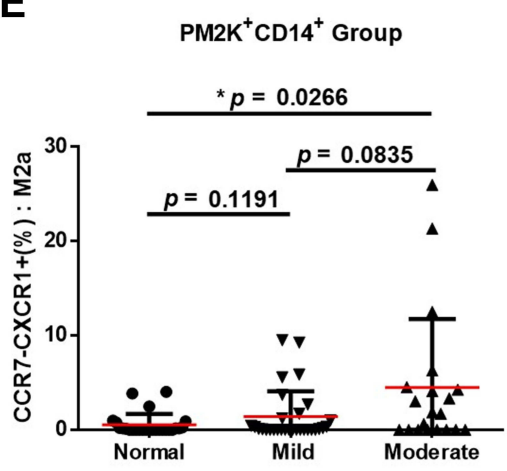

H

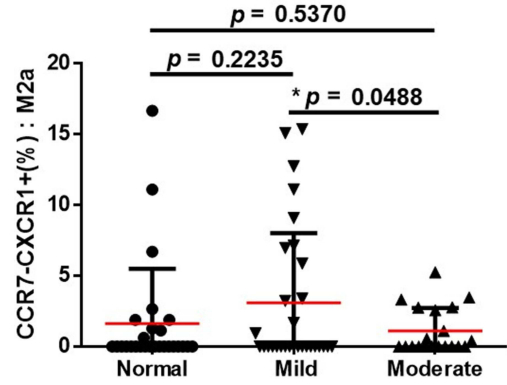

B

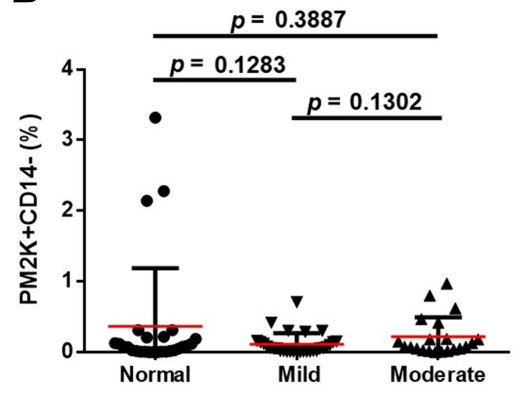

D

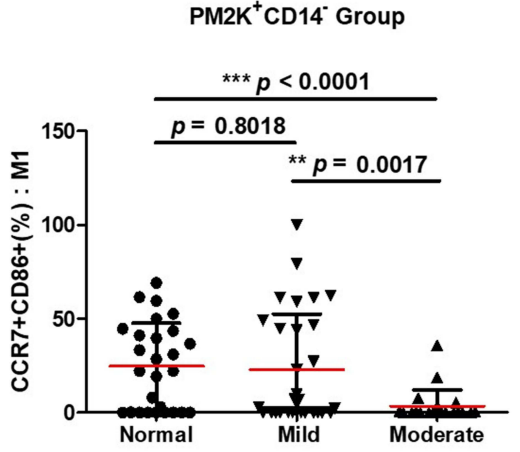

F

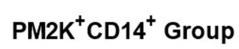

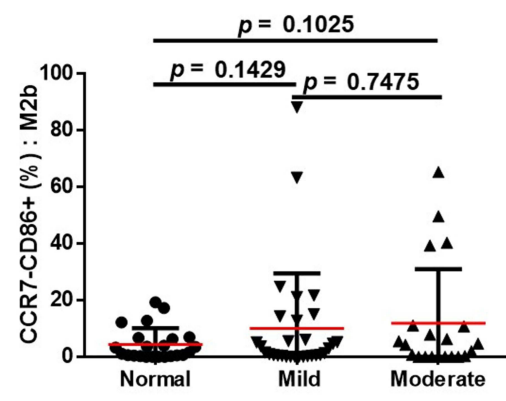

I

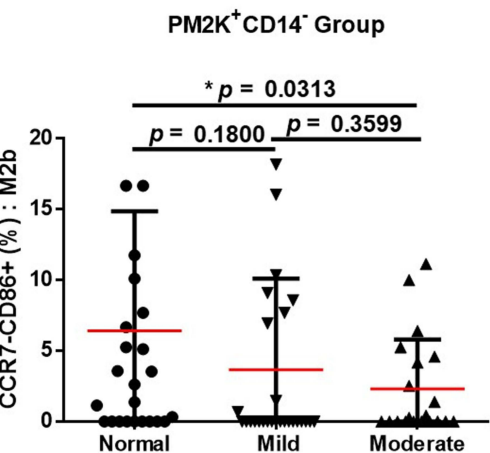

G

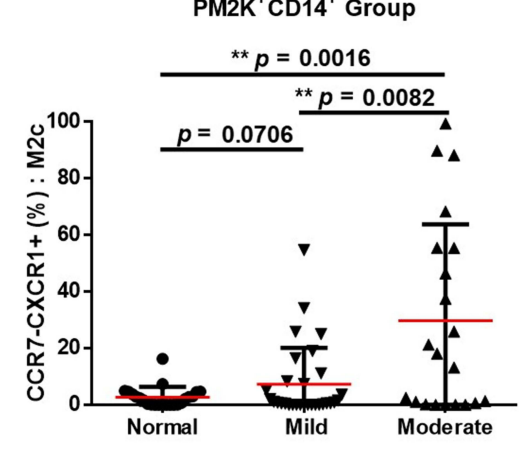

J

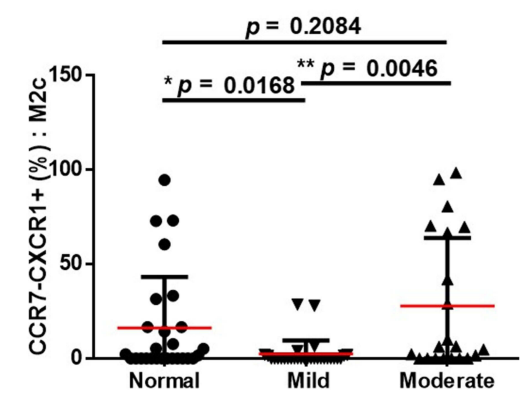

Figure $5 \mathrm{PM}-2 \mathrm{~K}^{+} \mathrm{CDI} 4^{+} / \mathrm{PM}-2 \mathrm{~K}^{+} \mathrm{CDI} 4^{-}$macrophages and their subsets in mild and moderate asthmatic children. The levels of $\mathrm{PM}-2 \mathrm{~K}^{+} \mathrm{CDI} 4^{+}$macrophage $(\mathrm{A})$ and $\mathrm{PM}$ $2 \mathrm{~K}^{+} \mathrm{CDI} 4^{-}$macrophage (B) were not significantly different between mild and moderate asthmatic children. The levels of PM-2K $\mathrm{K}^{+} \mathrm{CDI} 4^{+}$macrophage $\mathrm{MI}$ subset $(\mathrm{C})$ and $\mathrm{PM}-$ $2 \mathrm{~K}^{+} \mathrm{CDI} 4^{-}$macrophage $\mathrm{MI}$ subset (D) were significantly decreased in moderate asthmatic children. The levels of $\mathrm{PM}-2 \mathrm{~K}^{+} \mathrm{CDI} 4^{+}$macrophage $\mathrm{M} 2 \mathrm{a}(\mathrm{E})$ and $\mathrm{M} 2 \mathrm{~b}(\mathbf{F})$ subsets were not significantly different between mild and moderate asthmatic children. The level of PM- $2 \mathrm{~K}^{+} \mathrm{CDI} 4^{+} \mathrm{M} 2 \mathrm{c}(\mathbf{G})$ subset was increased in moderate asthmatic children. The levels of and M2b (I) subset were not significantly different between mild and moderate asthmatic children; in the contrast, the levels of PM-2K ${ }^{+} \mathrm{CDI} 4^{-} \mathrm{M} 2 \mathrm{a}(\mathbf{H})$ were borderline decreased between mild and moderate asthmatic children. The level of PM-2 $\mathrm{K}^{+} \mathrm{CDI} 4^{-} \mathrm{M} 2 \mathrm{c}$ macrophage subset (J) was significantly increased in moderate asthmatic children. *Represent $\mathrm{p}<0.05$, **Represent $\mathrm{p}<0.0 \mathrm{I}$, and $* * *$ Represent $\mathrm{p}<0.00 \mathrm{I}$. Data were expressed as mean \pm standard deviation (SD). 
A

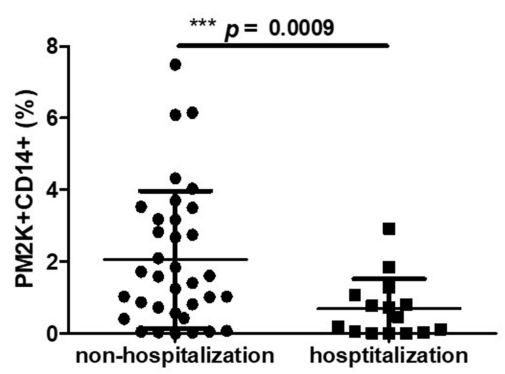

C

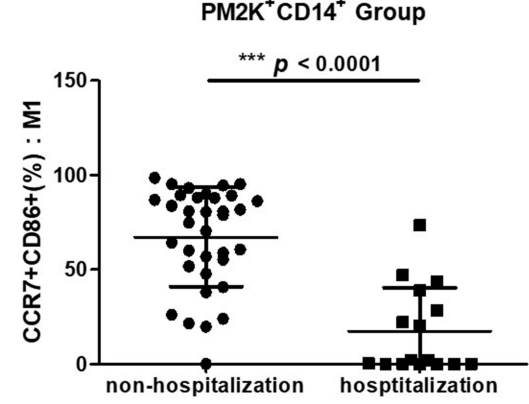

E

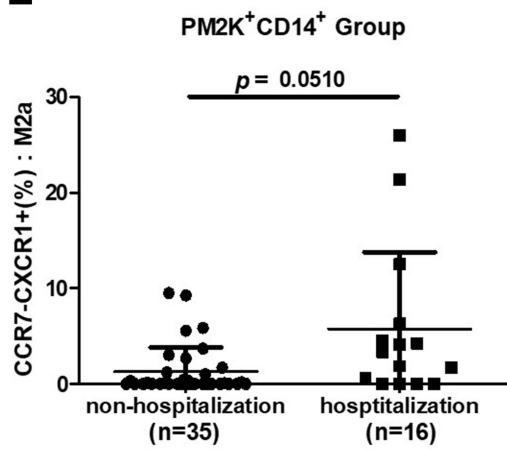

H PM2K ${ }^{+}$CD14- Group

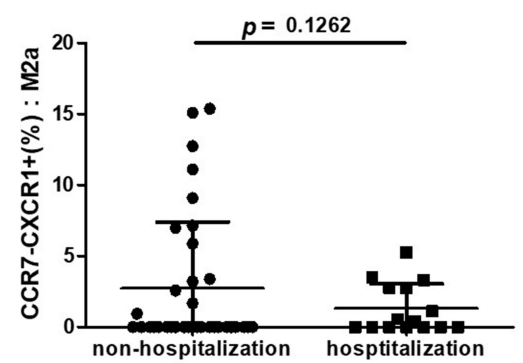

B

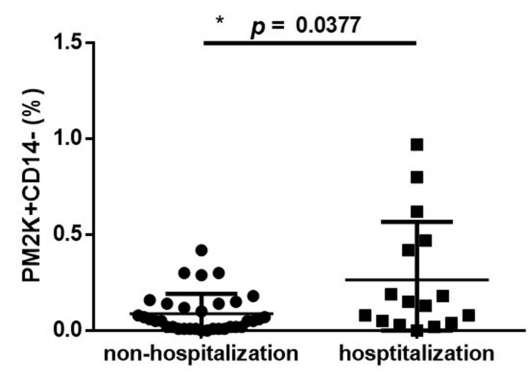

D

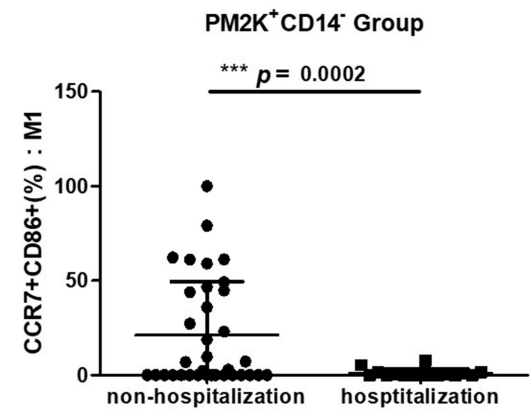

F

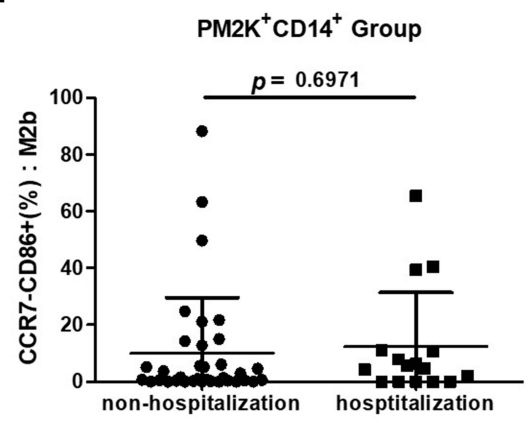

G

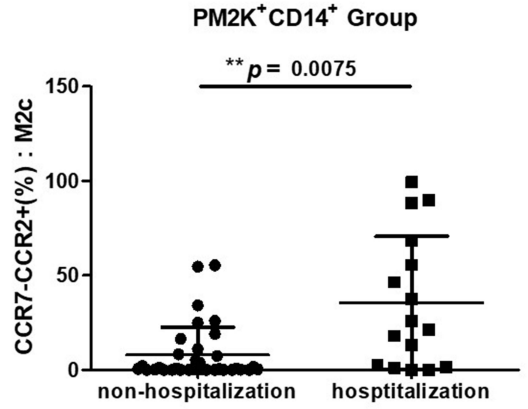

J

$\mathrm{PM}^{+} \mathrm{K}^{+} \mathrm{CD} 14^{-}$Group

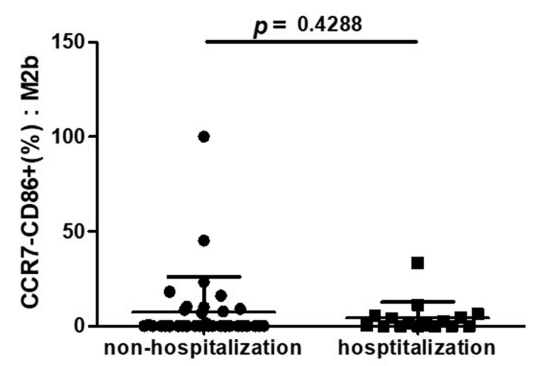

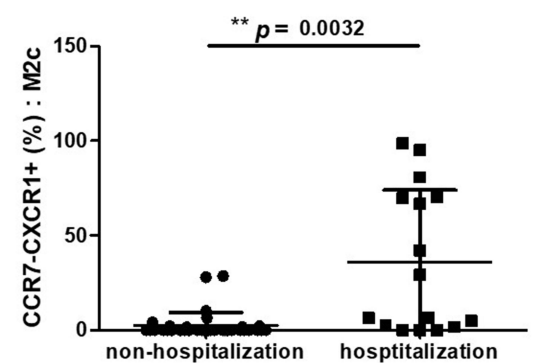

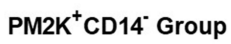

Figure 6 PM-2 $\mathrm{K}^{+} \mathrm{CDI} 4^{+} / \mathrm{PM}-2 \mathrm{~K}^{+} \mathrm{CDI} 4^{-}$macrophages and their subsets in asthmatic children requiring hospitalization during exacerbation. The levels of PM-2K ${ }^{+} \mathrm{CDI} 4^{+}$ macrophages (A) were decreased while PM-2 $\mathrm{K}^{+} \mathrm{CDI} 4^{-}$macrophages were increased in asthmatic exacerbation children requiring hospitalization. The levels of PM$2 \mathrm{~K}^{+} \mathrm{CDI} 4^{-}$macrophages (B) were mildly increased between asthmatic children requiring and not requiring hospitalization. The levels of PM- $2 \mathrm{~K}^{+} \mathrm{CD} / 4^{+}$macrophage subset (C) and PM-2 $\mathrm{K}^{+} \mathrm{CDI} / 4^{-}$macrophage subset (D) were decreased in asthmatic children requiring hospitalization. The levels of PM-2K $\mathrm{K}^{+} \mathrm{CD} / 4^{+}$macrophage M2a (E) and M2b (F) subsets were not significantly different between asthmatic children requiring and not requiring hospitalization. The levels of PM-2 $\mathrm{K}^{+} \mathrm{CD} \mathrm{I4} 4^{+}$macrophage M2c $(\mathbf{G})$ subset were increased in asthmatic children requiring hospitalization. The levels of PM-2K ${ }^{+} \mathrm{CDI} 4^{-}$macrophage $\mathrm{M} 2 \mathrm{a}(\mathbf{H})$ and $\mathrm{M} 2 \mathrm{~b}$ (I) subsets were not significantly different between asthmatic children requiring and not requiring hospitalization. The levels of PM-2 $\mathrm{K}^{+} \mathrm{CD} / 4^{-}$macrophage $\mathrm{M} 2 \mathrm{c}(\mathrm{J})$ subset were increased in asthmatic children requiring hospitalization. *Represent $\mathrm{p}<0.05$, **Represent $\mathrm{p}<0.01$, and ***Represent $\mathrm{p}<0.001$. Data were expressed as mean \pm standard deviation (SD). 
A

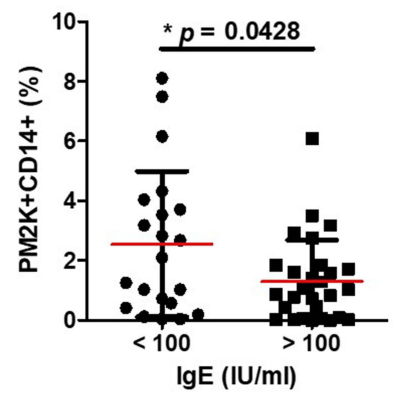

C

$\mathrm{PM}^{+} \mathrm{K}^{+} \mathrm{CD} 14^{+}$Group

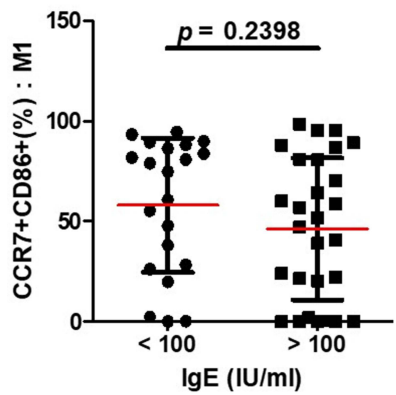

E

PM2K $^{+}$CD14 ${ }^{+}$Group

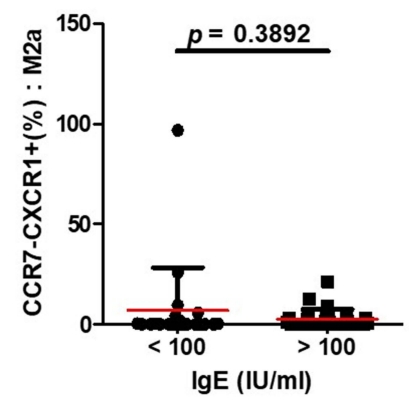

H

PM2K ${ }^{+}$CD14- Group

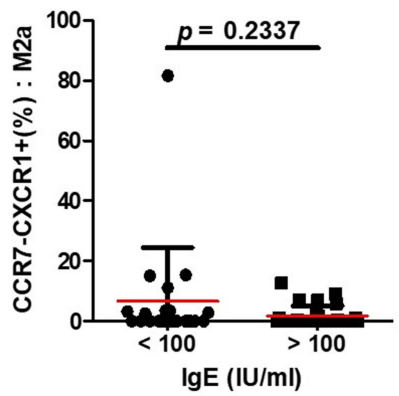

B

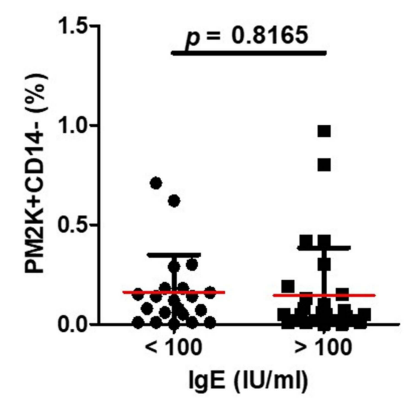

D

$\mathrm{PM}^{\circ} \mathrm{K}^{+} \mathrm{CD} 14^{-}$Group

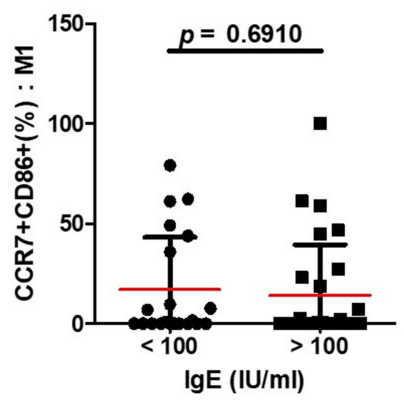

F

PM2K $^{+}$CD14 ${ }^{+}$Group

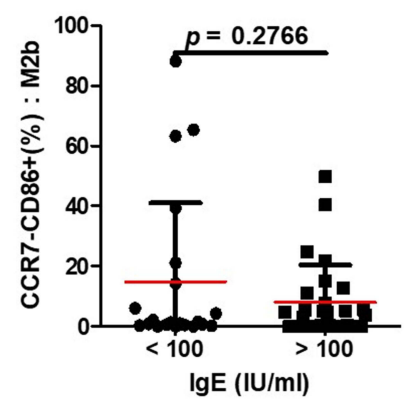

$\mathrm{PM}^{+} \mathrm{K}^{+} \mathrm{CD} 14^{-}$Group

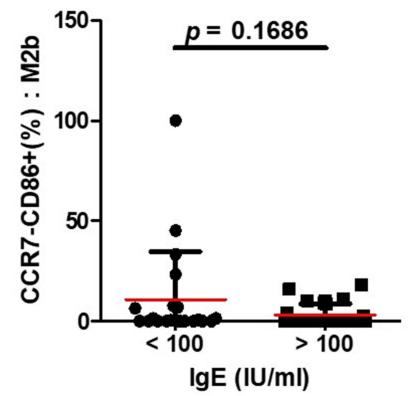

G

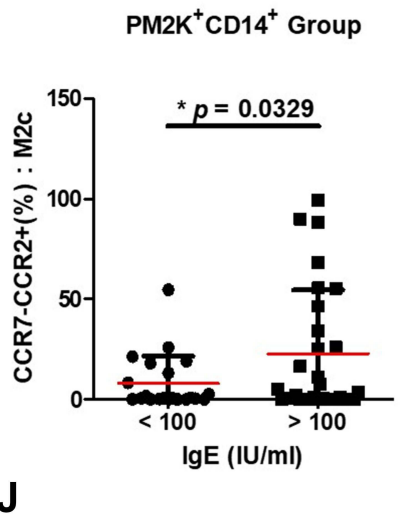

$\mathrm{PM}^{+} \mathrm{K}^{+} \mathrm{CD} 14^{-}$Group

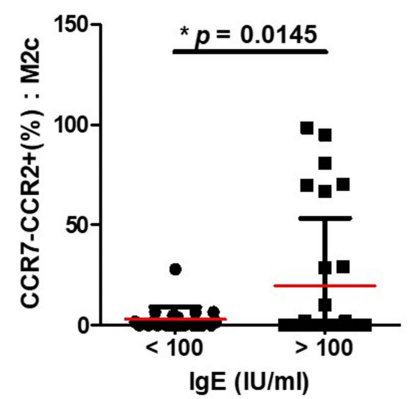

Figure 7 The association between $\mathrm{PM}-2 \mathrm{~K}^{+} \mathrm{CDI} / 4^{+} / \mathrm{PM}-2 \mathrm{~K}^{+} \mathrm{CD} / 4^{-}$macrophages with their subsets and IgE levels in asthmatic children. The levels of $\mathrm{PM}-2 \mathrm{~K}^{+} \mathrm{CDI} / 4^{+}$ macrophage (A), but not PM-2 $\mathrm{K}^{+} \mathrm{CDI} 4^{-}$macrophage (B), were increased in asthmatic children with higher lgE levels. The levels of PM-2 $\mathrm{K}^{+} \mathrm{CD} / 4^{+}(\mathrm{C})$ and $\mathrm{PM}$ -

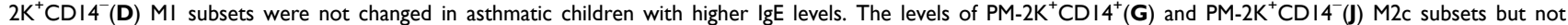
M2a $(\mathbf{E}$ and $\mathbf{H})$ nor M2b (F and $\mathbf{I})$ subsets were increased in asthmatic children with higher lgE levels. *Represent $\mathrm{p}<0.05$. Data were expressed as mean \pm standard deviation (SD). 
Lung macrophages link both innate and adaptive immune responses in allergic airway inflammatory responses and have been suggested to play critical roles in the pathogenesis of asthma. Immunohistochemically, PM-2K recognizes most tissue macrophages in lymphoreticular organs such as the thymus, spleen, lymph node, and tonsil. ${ }^{13}$ Since macrophages are involved in the pathogenesis of asthma, our study provided a rational approach to investigate the pathogenesis of asthma by studying PM$2 \mathrm{~K}$-positive circulating macrophages in children with asthma. In the present study, we found that the percentage of $\mathrm{PM}-2 \mathrm{~K}^{+} \mathrm{CD} 14^{+}$cells but not $\mathrm{PM}-2 \mathrm{~K}^{+} \mathrm{CD} 14^{-}$cells was decreased in children with asthma. In addition, M2 subsets of $\mathrm{PM}-2 \mathrm{~K}^{+} \mathrm{CD} 14^{+}$cells were increased in children with asthma. Moreover, the levels of M1 and M2c distinguished the severity of asthma and predicted the need for hospitalization during an asthma exacerbation. These findings suggested dynamic changes between circulating and tissue macrophages in contributing to and regulating local inflammation in the airways of children with asthma.

In previous animal asthma models, lipoproteinassociated phospholipase A2 (Lp-PLA2) gene knockout mice revealed that inflammatory responses induced by airway allergen sensitization were significantly decreased, which may contribute to increased IL-10 production and M2c macrophage polarization. ${ }^{14,15}$ In contrast, in surfactant protein A (SP-A) gene knockout mice, the inflammatory response after exposure to allergens was significantly increased due to high IL-13 expression with M2a macrophage polarization. ${ }^{16}$ Hence, the level of M2c macrophages could be utilized as a marker in chronic inflammatory lung disorders such as asthma, both for disease severity and in guiding the treatment strategy. ${ }^{17} \mathrm{In}$ contrast to M2a cells, M2c cells have an anti-inflammatory ability due to greater IL-10 expression involved in the resolution of lung inflammation and initiating tissue repair by releasing IL-10. Therefore, M2c cells can be considered a significant macrophage subset to participate in initiating inflammation resolution, and these processes may occur by upregulating CD163 and CD206. ${ }^{17}$

In the present study, we revealed that increased circulating M2c subsets were closely associated with not only the severity but also the requirement for hospitalization during asthma exacerbations. For the first time in the literature, this study proved the role of M2c subsets in human subjects. Exposure to pathogens or allergens alters the microenvironment in the tissue and leads to the polarization of macrophages, depending on a variety of cytokines produced by lung epithelial cells and innate immune cells. ${ }^{18}$ After polarization, these macrophage subsets express various cell surface markers and cytokines/ chemokines. For example, under LPS, IFN-r, and GMCSF stimulation, macrophages are polarized to the M1 subset, producing proinflammatory Th1 cytokines and chemokines with a predominant role in pathogen clearance and tissue damage. ${ }^{9}$ With the stimulation of IL-4/IL-13, macrophages are polarized to the M2a subset, activating Th2 cells and recruiting eosinophils into the lungs and they are involved in allergic inflammation. ${ }^{19}$ The M2b subset can be elicited upon the stimulation of IL-1R ligands, immune complexes, and LPS, while M2c can be induced upon the stimulation of IL-10, TGF- $\beta 1$, and glucocorticoids. M2c exerts an anti-inflammatory function during recovery, and both $\mathrm{M} 2 \mathrm{~b}$ and M2c predominantly participate in tissue remodeling and fibrosis. ${ }^{20}$

In our present study, we found that all M2 subsets including M2a, M2b, and M2c subsets were increased in asthmatic children in comparison to those in normal children. Moreover, the levels of increased M2a and M2c subsets were positively related to the severity, and the level of increased M2c subsets predicted the need for hospitalization during asthma exacerbations. While the M1 subset was not changed in asthmatic children, the M1 subset was significantly decreased in asthmatic children with moderate severity compared to asthmatic children with mild severity, and the degree of decrease of the M1 subset also predicted the need for hospitalization. These data suggested that the allergic immune response plays a critical role in the pathogenesis of childhood asthma, and impaired balance and regulation between not only local but also circulating M1 and M2 subsets may exist in asthmatic children.

It is known that asthma is a heterogeneous disease that varies considerably across the life course and shows differences between childhood-onset and adult-onset courses. ${ }^{12}$ For example, childhood asthma is known for its male predominance before puberty, high remission rate, and rare mortality. Adult asthma is known for its female predominance, low remission rate, and relatively higher mortality. Childhood asthma and adult asthma share different factors associated with severity. Interestingly, in comparison to our previous work exploring circulating macrophages in asthmatic adults, ${ }^{11} \mathrm{PM}-2 \mathrm{~K}^{+} \mathrm{CD} 14^{-}$and PM- $2 \mathrm{~K}^{+} \mathrm{CD} 14^{+}$cells were predominantly decreased in asthmatic adults, while only $\mathrm{PM}-2 \mathrm{~K}^{+} \mathrm{CD} 14^{+}$cells were decreased in asthmatic children, as also shown in the 
present study. The imbalance between M1 and M2 subsets is also quite different. In the present study, an increased M2 subset was found in asthmatic children, and the levels of increased M2/decreased M1 subset were related to the severity and the need for hospitalization. Very interestingly, these findings were in contrast to our previous work in asthmatic adults, where the M1 subset was increased and the M2 subset was decreased, and the levels of increased M1/decreased M2 subsets were positively correlated with severity.

In addition, previous research has revealed that elevated IgE levels were found in patients with atopic status, as it provides a linkage between antigen recognition and the effector function of acute-phase inflammatory cells such as mast cells and basophils. IgE plays an important role in the allergic inflammatory pathogenesis of bronchial asthma; therefore, it can be considered a cause of allergic asthma. ${ }^{21,22}$ In the present study, elevated IgE levels were positively associated with the M2c subset. Currently, little evidence suggests that IgE antibodies may activate and recruit macrophages toward tumors, but little is known about the effects of IgE IgE-Fce-receptor interactions on the downstream effects of macrophage polarization. ${ }^{23}$ The observation of elevated M2c levels in patients with elevated IgE indicates a need for further studies of the interaction between $\operatorname{IgE}$ and macrophage polarization.

\section{Conclusion}

The findings of the present study suggest that the use of multicolor flow cytometry with a small amount of peripheral blood to obtain the levels of circulating macrophages and their subsets can discriminate the severity of asthma and the requirement for hospitalization during exacerbations in children with asthma. These findings offer a new approach for further understanding the pathogenic mechanisms of childhood asthma and may be useful to study other childhood immune diseases associated with macrophages. M2c subsets, as a potential biomarker for clinical applications, requires further investigation in an expanded study population to test the clinical utility of these findings.

\section{Acknowledgments}

This work was supported both by the Research Center for Environmental Medicine, Kaohsiung Medical University, and Kaohsiung, Taiwan from The Featured Areas Research Center Program within the framework of the Higher Education Sprout Project by the Ministry of
Education (MOE) in Taiwan and by Kaohsiung Medical University Research Center Grant (KMU-TC109A01); and by grants the Kaohsiung Municipal Siaogang Hospital Research Foundation (S-109-05, I-109-02).

\section{Disclosure}

The authors report no conflicts of interest in this work.

\section{References}

1. Fish JE, Peters SP. Airway remodeling and persistent airway obstruction in asthma. J Allergy Clin Immunol. 1999;104(3 Pt 1):509-516. doi:10.1016/S0091-6749(99)70315-5

2. Wu Z, Zhang Z, Lei Z, Lei P. CD14: biology and role in the pathogenesis of disease. Cytokine Growth Factor Rev. 2019;48:24-31. doi:10.1016/j.cytogfr.2019.06.003

3. Kapellos TS, Bonaguro L, Gemünd I, et al. Human monocyte subsets and phenotypes in major chronic inflammatory diseases. Review. Front Immunol. 2019;10(2035). doi:10.3389/fimmu.2019.02035

4. Wilson MS, Wynn TA. Pulmonary fibrosis: pathogenesis, etiology and regulation. Mucosal Immunol. 2009;2(2):103-121. doi:10.1038/ mi.2008.85mi200885

5. Porcheray F, Viaud S, Rimaniol AC, et al. Macrophage activation switching: an asset for the resolution of inflammation. Clin Exp Immunol. 2005;142(3):481-489. doi:10.1111/j.1365-2249.2005.02934.x

6. Moreira AP, Hogaboam CM. Macrophages in allergic asthma: fine-tuning their pro- and anti-inflammatory actions for disease resolution. $J$ Interferon Cytokine Res. 2011;31(6):485-491. doi:10.1089/jir.2011.0027

7. Pilling D, Fan T, Huang D, Kaul B, Gomer RH. Identification of markers that distinguish monocyte-derived fibrocytes from monocytes, macrophages, and fibroblasts. PLoS One. 2009;4(10):e7475. doi:10.1371/journal.pone.0007475

8. Benoit M, Desnues B, Mege JL. Macrophage polarization in bacterial infections. J Immunol. 2008;181(6):3733-3739. doi:10.4049/ jimmunol.181.6.3733

9. Murray PJ. Macrophage polarization. Annu Rev Physiol. 2017;79:541-566. doi:10.1146/annurev-physiol-022516-034339

10. Saradna A, Do DC, Kumar S, Fu QL, Gao P. Macrophage polarization and allergic asthma. Transl Res. 2018;191:1-14. doi:10.1016/j. trs1.2017.09.002

11. Hung CH, Wang CC, Suen JL, et al. Altered pattern of monocyte differentiation and monocyte-derived TGF-beta1 in severe asthma. Sci Rep. 2018;8(1):919. doi:10.1038/s41598-017-19105-z

12. Trivedi M, Denton E. Asthma in children and adults-what are the differences and what can they tell us about asthma? Front Pediatr. 2019;7:256. doi:10.3389/fped.2019.00256

13. Takeya M, Tsuchiya T, Shimokawa Y, Takahashi K. A new monoclonal antibody, PM-2K, specifically recognizes tissue macrophages but not blood monocytes. J Pathol. 1991;163(4):315-321. doi:10.1002/path.1711630408

14. Jiang Z, Ravaioli G, Fehrenbach ML, et al. Lipoprotein associated phospholipase A2 (LP-PLA2)/platelet activating factor acetyl hydrolase (PAF-AH) deficiency is associated with increased numbers of M2 macrophages in the lung during the allergic airway response in mice. In: C37 Mediators of Asthma and Allergic Lung Disease. American Thoracic Society; 2012:A4302-A4302.

15. Jiang Z, Kokalari B, Redai IG, Hanman N, Macphee CH, Haczku A. Lack of lipoprotein associated phospholipase A2 (Lp-PLA2) enhanced phagocytosis and IL-10 expression and decreased NF-kB activation in CD206+ M2 macrophages in gene deficient mice. In: B21 Airway Host Defense. American Thoracic Society; 2014:A2485A2485. 
16. Jiang Z, Kokalari B, Redai IG, et al. Lack of surfactant protein A (SP-A) enhances airway inflammation and hyperresponsiveness after ozone (O3) or Aspergillus fumigatus (Af) exposure in association with increased presence of IL-13+/CD206+ alternatively activated (M2) macrophages. In: B101 Airway Epithelial Cell Activation and Dysfunction. American Thoracic Society; 2013:A3554-A3554.

17. Jiang Z, Zhu L. Update on the role of alternatively activated macrophages in asthma. J Asthma Allergy. 2016;9:101-107. doi:10.2147/jaa.S104508

18. Gordon S. Alternative activation of macrophages. Nat Rev Immunol. 2003;3(1):23-35. doi:10.1038/nri978

19. Girodet PO, Nguyen D, Mancini JD, et al. Alternative macrophage activation is increased in asthma. Am J Respir Cell Mol Biol. 2016;55 (4):467-475. doi:10.1165/rcmb.2015-0295OC

20. Mantovani A, Sica A, Sozzani S, Allavena P, Vecchi A, Locati M. The chemokine system in diverse forms of macrophage activation and polarization. Trends Immunol. 2004;25(12):677-686. doi:10.1016/j.it.2004.09.015
21. Froidure A, Mouthuy J, Durham SR, Chanez P, Sibille Y, Pilette C. Asthma phenotypes and IgE responses. Eur Respir J. 2016;47 (1):304-319. doi:10.1183/13993003.01824-2014

22. Matucci A, Vultaggio A, Maggi E, Kasujee I. Is IgE or eosinophils the key player in allergic asthma pathogenesis? Are we asking the right question? Respir Res. 2018;19(1):113. doi:10.1186/s12931-018-0813-0

23. Pellizzari G, Hoskin C, Crescioli S, et al. IgE re-programs alternatively-activated human macrophages towards pro-inflammatory anti-tumoural states. EBioMedicine. 2019;43:67-81. doi:10.1016/j. ebiom.2019.03.080
Journal of Inflammation Research

\section{Publish your work in this journal}

The Journal of Inflammation Research is an international, peerreviewed open-access journal that welcomes laboratory and clinical findings on the molecular basis, cell biology and pharmacology of inflammation including original research, reviews, symposium reports, hypothesis formation and commentaries on: acute/chronic inflammation; mediators of inflammation; cellular processes; molecular

\section{Dovepress}

mechanisms; pharmacology and novel anti-inflammatory drugs; clinical conditions involving inflammation. The manuscript management system is completely online and includes a very quick and fair peerreview system. Visit http://www.dovepress.com/testimonials.php to read real quotes from published authors. 